\title{
Farklı Voleybol Liglerindeki Takımlarda Görev Alan Voleybol Antrenörlerinin Sosyal İyilik Hali Yönünden Karşılaştırılması *
}

\author{
The Comparison of Volleyball Coaches in Different Volleyball Leagues in \\ Terms of Social Wellness ${ }^{\star}$
}

\author{
Arda YOLAÇ ${ }^{* *}$ \\ Serap MUNGAN AY ${ }^{* * *}$ iD
}

\begin{abstract}
Öz
Bu çalışmanın amacı farklı voleybol liglerindeki takımlarda görev alan voleybol antrenörlerinin sosyal iyilik hallerinin incelenmesidir. Bu bağlamda çalışmanın örnek grubunu, Türkiye - 2018-2019 sezonunda, vize yaptıran 200 voleybol antrenörü oluşturmaktadır. Araştırmada veri toplama araçları iki bölümden oluşmaktadır. Birinci bölümde kişisel bilgi formuna ek olarak, Corbin (2005) tarafından geliştirilmiş, Geçerlilik ve güvenirlilik çalışması Odabaş (2017) tarafından yapılmış olan İyilik Hali Kendini Algılama Ölçeği kullanılmıştır. Verilerin değerlendirilmesi aşamasında SPSS 23 paket programı kullanılmış olup, betimsel istatistikler, Bağımsız t-testi ve Anova analizlerinden faydalanılmıştır. Analiz sonuçlarına göre katılımcıların cinsiyetlerine, medeni durumlarına, gelir düzeylerine ve çalışma yıllarına göre sosyal iyilik halleri farklılık göstermemektedir. Sonuçların farklı voleybol liglerinde görev yapan antrenörlerin iyilik halleri, sosyo-demografik özelliklerine göre farklılık göstermediği söylenebilir.
\end{abstract}

Anahtar Kelimeler: Voleybol, lig, antrenör, sosyal iyilik hali

\section{Abstract}

The aim of this study is to investigate the social wellness status of the volleyball coaches working for the teams which are in different leagues. In this sense; 200 volleyball coaches from Turkey who were offical for 2018-2019 season are chosen for this study. Data collection for this study consists of two parts. In the first part; wellness self-understanding scale which was developed by Corbin (2005) is used in addition to the personal information form. The validity and reliability study of this scale was carried out by Odabaş (2017). At the stage of data evaluation, SPSS 23 package program was used and descriptive statistics, Independent t-test and Anova analysis were used. According to the results of the analysis, social wellness of the participants doesn't differ according to their gender, marital status, income level and working years.

* Bu çalışma, "Farklı voleybol liglerindeki takımlarda görev alan voleybol antrenörlerinin sosyo-ekonomik faktörler ve iyilik hali yönünden karşılaştırılması" isimli yüksek lisans tezinden üretilmiştir. Marmara Üniversitesi Sağlık Bilimleri Enstitüsü Beden Eğitimi ve Spor Anabilim Dalı 2020.

** Yüksek lisans öğrencisi, Marmara Üniversitesi, Sağlık Bilimleri Enstitüsü, ardayolac@gmail.com

*** Dr.Öğr.Üyesi, Marmara Üniversitesi, Spor Bilimleri Fakültesi, smunganay@marmara.edu.tr 
It can be said that the results don't show any difference according to the wellness and socio-demographic characteristics of the coaches working in different volleyball leagues.

Keywords: Volleyball, league, coach, social wellness

\section{GİRIS}

İnsanoğlu varoluşundan bu yana kendini tanımaya ve nasıl daha iyi olabilirim diye kendini geliştirebileceğini ve yaşamı nasıl daha yaşanabilir olabileceğini araştırmıştır. Pek çok filozof ve bilim insanı bu sorulara tarih boyunca yanıt aramışlardır. İyilik hali kavramı da bu arayışların bir neticesi olarak 1990'lı yıllarda insanın daha iyi ve sağlıklı yaşayabilme konusunda modern dünya insanının yaşam biçimini inceleyerek geliştirdiği popüler kavramlarından biri haline gelmiştir (Duran ve Tezer, 2005). Genel iyilik halinin geliştirilmesi ve yaygınlaştırılması için günümüzde hem kuramsal hem de uygulamalı olarak ayrıntılı çalışmalar yapılmaktadır. İyilik halini yaygınlaştırma ve hastalıkları önleme için sahada çalışmalar yapılmaktadır (Baltaş, 2000). Modern iyilik hali akımının iyilik haline yönelik çalışmaları Halbert Dunn (1961)'ın çalışmalarıyla birlikte başlamış, iyilik halini "bireyin kapasitesinin yettiği potansiyeli maksimize etmeye yönelik yöneltilen bütünleştirilmiş bir işlevsellik metodu" olarak tanımlamış ve danışmanların, kişilerin yüksek seviye iyilik haline ulaşmalarına yardım etmek için eşsiz bir konumda olduklarını öne sürmüştür (Akt: Hattie ve ark., 2004). Archer ve ark. (1987) tarafından yapılan iyilik hali tarifi ise iyilik hali, beden, bilinç ve öz birleşiminden meydana gelen maksimum işlerliği yükseltme yöntemi olarak tanımlanmıştır. (Akt: Doğan, 2004). Bu bağlamda, "Sosyal iyilik hali birinin başkaları tarafından destekleyici olarak algılanmasına da ek olarak ailesi, arkadaşları ya da tanıdıklar aracılığıyla birinin sosyal destek algısıdır. Birinin duygusal iyilik hali seviyesine kendi katkısı ve özsaygısıdır." (Milroy ve ark. 2013). Birey, sosyalleşmesi süresince her gün karşılaştığı sayısız olayların, diğer fertlerin, sosyo-ekonomik yapının, fiziksel çevrenin ve daha birçok faktörün etkisinde kalmaktadır (Oka, 1986). Hem kişinin hem de toplumun sürekli olarak gelişim kaydedebilmesi ve bilgi üretebilme imkanına kavuşması için, sürekli olarak sosyal ve ekonomik açıdan beslenmesi gerekmektedir. Sosyo ekonomik gelişim birbirinden ayrı düşünülmemesi gereken kavramlardır. Bir ülkede fert başına düşen milli gelir ve kalkınma hızı ne kadar yüksek olursa olsun, o ülkede sosyal ve kültürel seviyenin gelişmemiş olması halinde, burada yeterli düzeyde sosyal ilerlemenin olmayacağının altı çizilmelidir (Fidan, 2002). Bu bağlamda çalışmanın amacı, farklı voleybol liglerindeki takımlarda görev alan voleybol antrenörlerinin sosyal iyilik hallerinin incelenmesidir.

\section{YÖNTEM}

Araştırma Modeli: Araştırmada İlişkisel Tarama Modeli kullanılmıştır. Tarama modeli, geçmişte ya da halen var olan bir durumu ortaya çıkarmayı amaçlayan bir çalışma olarak tanımlanmaktadır (Karasar, 2010).

Araştırma Grubu: Araştırmanın örnekleminin belirlenmesinde olasılıksız örnekleme türlerinden kolayda örneklem yöntemi kullanılmıştır. Bu bağlamda çalışmanın örneklemini; Türkiye'de 20182019 sezonunda, vize yaptıran 200 voleybol antrenörü oluşturmaktadır. 
Araştırmada veri toplama araçları iki bölümden oluşmaktadır.

Kişisel Bilgi Formu: Araştırmaya katılan antrenörlerin cinsiyet, yaş, eğitim durumu gibi bilgileri elde etmek amacıyla araştırmacı tarafından hazırlanan kişisel bilgi formu kullanılmıştır.

İilik Hali Kendini Algıma Ölçeği: Orijinali Corbin (2005) tarafından geliştirilmiş, Türkiye’deki geçerlilik ve güvenirlilik çalışması Odabaş (2017) tarafından yapılmış olan İyilik Hali Kendini Algılama Ölçeği kullanılmıştır. Ölçek toplam 15 maddeden oluşmakta ve maddeleri "çok katılıyorum, katılıyorum, katılmıyorum, hiç katılmıyorum” şeklinde ifade edilen dörtlü likert türü bir ölçektir.

Verilerin Değerlendirilmesi: Verilerin çözümlenmesi sürecinde SPSS 23 paket programı kullanılmıştır. Betimsel analizler için frekans (f), aritmetik ortalama, yüzde (\%) ve standart sapma (s) değerlerinden faydalanılmıştır. Bağımsız t-testi analizi ve ANOVA analizlerinden yararlanılmıştır. Gruplar arası farklılık belirlenmesi için ise Post-Hoc testlerinden Scheffe, LSD ve TUKEY testleri uygulanmıştır.

\section{BULGULAR}

Tablo 1. Antrenörlerin sosyal iyilik hallerinin cinsiyete göre t-testi sonuçları

\begin{tabular}{ccccccc}
\hline Cinsiyet & $\mathbf{N}$ & $\mathbf{X}$ & $\mathbf{S}$ & $\mathbf{s d}$ & $\mathbf{t}$ & $\mathbf{p}$ \\
\hline Erkek & 164 & 10,59 & 1,31 & 198 & $-1,116$ & .266 \\
Kadın & 36 & 10,86 & 1,09 & & & \\
\hline
\end{tabular}

Tablo 1'de görüleceği üzere antrenörlerin sosyal iyilik boyutundan aldıkları toplam puanlar cinsiyete göre anlamlı bir farklılık göstermemiştir $\left(\mathrm{t}_{(198)}=-1.116, \mathrm{p}>.05\right)$. Erkeklerin sosyal iyilik puanları $(\mathrm{X}=10,59)$ ile kadınların sosyal iyilik puanları $(\mathrm{X}=10,86)$ birbirine yakın çıkmıştır. Buna göre cinsiyet, antrenörlerin sosyal iyilikleri üzerinde anlamlı bir farklılık ortaya koymamıștır.

Tablo 2. Antrenörlerin sosyal iyilik hallerinin medeni duruma göre t-testi sonuçları

\begin{tabular}{ccccccc}
\hline Medeni Durum & $\mathbf{N}$ & $\mathbf{X}$ & $\mathbf{S}$ & $\mathbf{s d}$ & $\mathbf{t}$ & $\mathbf{p}$ \\
\hline Evli & 90 & 10,56 & 1,28 & 198 & -.780 & .436 \\
Bekâr & 110 & 10,70 & 1,28 & & & \\
\hline
\end{tabular}

Tablo 2'de görüleceği üzere antrenörlerin sosyal iyilik boyutundan aldıkları toplam puanlar medeni duruma göre manidar bir farklılık göstermemiştir $\left(\mathrm{t}_{(198)}=-.780, \mathrm{p}>.05\right)$. Evlilerin sosyal iyilik puanları $(\mathrm{X}=10,56)$ ile bekarların sosyal iyilik puanları $(\mathrm{X}=10,70)$ birbirine yakın çıkmıştır. Buna göre görev medeni durum, antrenörlerin sosyal iyilikleri üzerinde anlamlı bir farklılık ortaya koymamıştır. 
Tablo 3. Antrenörlerin sosyal iyilik hallerinin gelirlerine göre Anova sonuçları

\begin{tabular}{|c|c|c|c|c|c|c|}
\hline Aylık Gelir & $\mathbf{N}$ & \multicolumn{2}{|c|}{$\mathrm{X}$} & \multicolumn{3}{|c|}{ Standart Sapma } \\
\hline 1603 ve altı & 32 & \multicolumn{2}{|c|}{10,7188} & \multicolumn{3}{|c|}{1,37335} \\
\hline $1604-3000$ aras 1 & 59 & \multicolumn{2}{|c|}{10,7797} & \multicolumn{3}{|c|}{1,28744} \\
\hline $3001-5000$ aras1 & 53 & \multicolumn{2}{|c|}{10,2642} & \multicolumn{3}{|c|}{1,42978} \\
\hline $5001-7000$ aras 1 & 26 & \multicolumn{2}{|c|}{10,8846} & \multicolumn{3}{|c|}{81618} \\
\hline $7001-9000$ aras1 & 17 & \multicolumn{2}{|c|}{10,7059} & \multicolumn{3}{|c|}{1,21268} \\
\hline 9001 ve üstü & 13 & \multicolumn{2}{|c|}{10,8462} & \multicolumn{3}{|c|}{1,14354} \\
\hline Varyansın Kaynağ & Kare & $\mathrm{amı}$ & Sd & Kareler Ortalaması & $\mathrm{F}$ & $\mathrm{p}$ \\
\hline Gruplararası & \multicolumn{2}{|c|}{4,253} & 5 &, 851 & 1,371 & ,768 \\
\hline Gruplariçi & \multicolumn{2}{|c|}{323,542} & 194 & 1,668 & & \\
\hline Toplam & \multicolumn{2}{|c|}{327,795} & 199 & & & \\
\hline
\end{tabular}

Tablo 3'de analiz sonuçlarına göre antrenörlerin sosyal iyilik puanlarında gelir düzeyleri açısından anlamlı bir farklılık yoktur, $\left(\mathrm{F}_{(5,194)}=1,371, \mathrm{p}>, 05\right)$. Başka bir deyişle antrenörlerin gelir düzeyleri, sosyal iyilik boyutundan aldıkları toplam puanlarda istatistiksel açıdan anlamlı bir fark ortaya koymamıştır.

Tablo 4. Faal antrenörlük yapılan yıla yönelik puanların istatistikleri

\begin{tabular}{|c|c|c|c|c|c|}
\hline Faal Antrenörlük Yılı & $\mathbf{N}$ & $\mathrm{X}$ & \multicolumn{3}{|c|}{ Standart Sapma } \\
\hline $1-5$ yll & 49 & 10,5714 & \multicolumn{3}{|c|}{1,32288} \\
\hline 6-10 yil & 48 & 10,6042 & \multicolumn{3}{|c|}{1,28394} \\
\hline $11-15$ yll & 31 & 10,5484 & \multicolumn{3}{|c|}{1,33763} \\
\hline $16-20$ yll & 27 & 10,5185 & \multicolumn{3}{|c|}{1,25178} \\
\hline $21-25$ yll & 23 & 10,9130 & \multicolumn{3}{|c|}{1,23998} \\
\hline 26 ve üstü & 22 & 10,9091 & \multicolumn{3}{|c|}{1,26901} \\
\hline Varyansın Kaynağı & Kareler Toplamı & sd & $\begin{array}{c}\text { Kareler } \\
\text { Ortalaması }\end{array}$ & $\mathrm{F}$ & $\mathrm{p}$ \\
\hline Gruplararası & 4,253 & 5 &, 851 &, 510 &, 768 \\
\hline Gruplariçi & 323,542 & 194 & 1,668 & & \\
\hline Toplam & 327,795 & 199 & & & \\
\hline
\end{tabular}

Tablo 4'de analiz sonuçlarına göre antrenörlerin sosyal iyilik puanlarında faal antrenörlük yaptıkları yıl açısından anlamlı bir farklılık yoktur, $\left(\mathrm{F}_{(5,194)}=.510, \mathrm{p}>, 05\right)$. Başka bir deyişle antrenörlerin faal antrenörlük yaptıkları yıl, sosyal iyilik boyutundan aldıkları toplam puanlarda istatistiksel açıdan anlamlı bir fark ortaya koymamıştır. 


\section{TARTIŞMA}

Çalışmanın amacı, farklı voleybol liglerindeki takımlarda görev alan voleybol antrenörlerinin sosyal iyilik hallerinin incelenmesidir. Bu amaç doğrultusunda elde edilen bulgular bu bölümde yorumlanmaya çalışılmıştır.

Antrenörlerin Sosyal İyilik Hallerinin Cinsiyete Göre t-testi Sonuçları değerlendirilmiş ve anlamlı bir farklılık bulunamamıştır. Yolaç (2020) yılında antrenörlerin sosyal iyilik hallerini değerlendiren çalışmasında toplam puanlar üzerinden istatistiksel olarak cinsiyete göre anlamlı bir farklılık bulmamıştır. Antrenörlerin sosyal iyilik boyutundan aldıkları toplam puanlar cinsiyete göre anlamlı bir farklılık göstermemiştir. $(\mathrm{t}(198)=-1.116$, p>.05). Erkeklerin sosyal iyilik puanları $(X=10,59)$ ile kadınların sosyal iyilik puanları $(\mathrm{X}=10,86)$ birbirine yakın çıkmıştır. Buna göre cinsiyet, antrenörlerin sosyal iyilikleri üzerinde anlamlı bir farklılık ortaya koymamıştır (Yolaç, 2020). 164 erkek 36 kadın antrenörle yapılan bu çalışmada kadın erkek oranı arasındaki fark oldukça fazladır. Konter (2007) yaptığı bir çalışmada cinsiyetlere göre liderlik gücü algılarını değerlendirmeye çalışmış bu çalışmada 86 erkek 5 kadın antrenör ile oluşturduğu çalışma grubunda yasal güç ve özdeleşim gücü dışında anlamlı bir farklılık bulamamıştır.

Gönülaçar (2010), voleybol antrenörleri ile yapmış olduğu bir çalışmada voleybol antrenörlerinin, antrenörlük yapan beden eğitimi öğretmenleri ile sosyoekonomik ve eğitim düzeylerini karşılaştırmış, bu araştırmadaki katılımcıların \%19'u bayan, \%81'i erkek olarak tespit etmiştir. Sporda cinsiyetler üzerinden antrenörlerin karşılaştırıldığı çalışmaların mevcut literatürde oldukça az olmasından kaynaklı olarak kesin sonuçlar çıkarmak ve genellemelere yönelmek çok mümkün olmamaktadır. Antrenörlerin Sosyal İyilik Hallerinin Medeni Duruma Göre t-Testi Sonuçları değerlendirilmiş istatistiksel olarak anlamlı bir farklılık bulunmamıştır. Antrenörlerin sosyal iyilik boyutlarından aldıkları toplam puanlar üzerinden istatistiksel değerlendirme yapan Yolaç (2020) evlilerin sosyal iyilik puanları $(X=10,56)$ ile bekarların sosyal iyilik puanlarını ( $X=10,70$ ) birbirine yakın bulmuştur ve istatistiksel olarak anlamlı bir farklılık olmadığını tespit etmiştir. Yıldız (2019) katılımcıların sürekli kaygı ve durumluk düzeylerini medeni durum ölçeğinde de karşılaştırmış ve istatistiksel olarak anlamlı bir farklılık bulmuştur (p<0.05). Emre (2008)'e göre ise, 265 antrenör ile yapmış olduğu olduğu bir çalışmada katılımcıların dağılımını evli ve bekar olan olarak tespit etmiştir. Kılınç (2012)'e göre antrenörlerin medeni durumu ile yaptığ 1 çalışmada ise medeni durum oranı \% 62'si evli ve \%38 de bekar olduğu görülmektedir. Bir başka çalışmada antrenörlerin medeni durumuna göre iş doyum düzeyleri incelenmiş ve istatistiksel olarak anlamlı bir farklılık bulunmamıştır (Doğan, 2016). Bu araştırma çalışmamızı destekler niteliktedir.

Antrenörlerin sosyal iyilik hallerinin gelirlerine göre değerlendirildiği incelemede istatistiksel olarak anlamlı bir farklılık bulunmamıştır. Yolaç (2020)'ın da voleybol antrenörlerin sosyal iyilik hallerini gelirlerine göre analiz ettiği çalışmasında istatiksel açıdan anlamlı bir farklılık bulunmadığını ortaya koymuştur. Bir başka çalışmada araştırmacı 450 denek antrenör ile sosyal iyi olma ölçeğine ait puanları sıralamış ve antrenörlerin gelir durumuna göre karşılaştırmıştır. Çalışma ölçeğinde 4 gelir 
grubu vardır. Orta sırada yer alan iki gelir grubu değişkeninde anlamlı bir farklılık olduğunu ortaya koymuştur (Bayraktar, 2019).

Doğan (2016) da antrenörlerin aylık gelirlerinin, içsel doyum ve dışsal doyum düzeyleri üzerinde yaptığı bir araştırmada, aylık gelirin arttıkça iş doyum düzeylerin de arttığı ortaya koymuştur. Bizim çalışmamız ile paralellik göstermese de sosyal iyilik hallerinde anlamlı bir farklılık yaratmayan gelir durumu iş doyum düzeyi ölçeğinde değerlendirildiğinde pozitif ivmelendiği söylenebilir.

Başka bir çalışmada (Toklu, 2010) antrenörlerin gelir seviyelerine göre öz yeterlilik ve liderlik özelliklerini incelenmiş ve araştırmaya katılan denekler arasında anlamlı bir farklılık bulunmamıştır.

Faal antrenörlük yapılan yıla yönelik puanların istatistikleri değerlendirildiğinde istatistiksel olarak anlamlı bir farklılık bulunmamıştır. Yolaç (2020) yaptığı çalışmada antrenörlerin sosyal iyilik puanlarında faal antrenörlük yaptıkları yıl açısından değerlendirmiş ve anlamlı bir farklılık olmadığ sonucuna varmıştır. Yıldız (2019) antrenörlerin sürekli kaygı ve durumluk düzeylerini antrenörlük yaptıkları yıllara göre karşılaştırmış ve anlamlı bir farklılık olmadığını bulmuştur.

\section{SONUÇ}

Bu araştırma, voleybol antrenörlerinin sosyal iyilik hallerinin cinsiyet, medeni durum, gelir düzeyleri ve faal antrenörlük süresi gibi değişkenlere etkisini incelemek amacıyla yapılmıştır.

Antrenörlerinin sosyal iyilik halleri cinsiyetleri açısından değerlendirildiğinde anlamlı bir farklılık bulunamamıştır. Antrenörlük mesleğinin ve beraberinde genel çalışma şartlarının zorlukları düşünüldüğünde, çalışmanın denek gurubunda da kadın antrenör sayısı oldukça düşük olması cinsiyet üzerinden değerlendirmeyi zorlaştırmıştır. Elde olan veriler ışı̆̆ında cinsiyetin sosyal iyilik halleri üzerinde etkili olmadı̆̆ı söylenebilir.

Antrenörlerinin sosyal iyilik halleri medeni durumları açısından değerlendirildiğinde anlamlı bir farklılık bulunamamıştır. Antrenörlük mesleğinin barındırdığı zorlukların yanımda yüksek tempo çalışma şartları, heyecan ve spora duyulan ilgi gibi değişkenler ile ele alındığında tüm bu parametreler antrenörlerin yaşam biçimi olduğu ve bu yaşam biçiminin kendi içinde belli zorlukları olduğu bilinse de medeni durumları üzerinde bir etki göstermediği söylenebilir.

Antrenörlerinin, sosyal iyilik halleri gelir düzeyleri açısından değerlendirildiğinde anlamlı bir farklılık bulunamamıştır. Antrenörlerin genel çalışma ihtiyaçlarının başında, diğer tüm mesleklerde olduğu gibi belli ölçüde kazanç elde etme amacı vardır. Kişilerin genel ekonomik ferahlığının sosyal iyilik halleri üzerinde etkili olduğu genel görüşe uygun düşse de çalışmada gelir düzeylerinin istatistiksel açıdan anlamlı bir fark yaratmadığı sonucuna varılmıştır. Bazı antrenörlerin gelirinin yeterince iyi olması, ancak bazı antrenörler ise antrenörlük mesleği ile birlikte farklı meslek kollarında da görev almaları sosyal iyilik halleri değişkeninde anlamlı bir farklılık bulunmamasına neden olmuş olabilir. 
Voleybol antrenörlerinin sosyal iyilik halleri faal antrenörlük süreleri açısından değerlendirildiğinde anlamlı bir farklılık bulunamamıştır. Antrenörlük mesleğinin önemli gereksinimlerinden biri de mesleğin yarattığı heyecan ve sevgi duygularıdır. Mesleğe yeni başlayanlar ve uzun süre faal olarak çalışan antrenörlerin meslekte geçirdikleri süre ölçütünde değerlendirildiklerinde herhangi bir anlamlı farklılık bulunmaması yarışmacı sporların kendi içinde yarattı̆̆ı heyecan unsuru ve branşa beslenen sevgi bağ parametrelerinde faal antrenörlerin sosyal iyilik halleri üzerinde anlamlı bir farklılık yaratmamasını açıklayabilir.

\section{KAYNAKLAR}

Archer, J. Probert, S. Gage, L. (1987). College students' attitudes toward wellness. Journal of College Student Personnel, 28(4), 311-317.

Baltaş, A. (2000) Ekip Çalışması ve Liderlik. İstanbul: Remzi Kitabevi.

Bayraktar, K. (2019). Antrenörlerin sosyal iyi oluş düzeylerinin psikolojik kırılganlığa olan etkisi. Yüksek Lisans Tezi, Karamanoğlu Mehmetbey Üniversitesi Sosyal Bilimleri Enstitüsü, Karaman.

Corbin, C. (2005). Fundamental Concepts Of Fitness And Wellness Toronto. McGraw-Hill.

Doğan, M., ve Akandere, M. (2016). Taekwondo Antrenörlerinin İş Doyumu Ve Tükenmişlik Düzeylerinin İncelenmesi. Yüksek Lisans Tezi, Selçuk Üniversitesi Sağlık Bilimleri Enstitüsü, Konya

Dunn, H. (1961). High - Level Wellness. Arlington, VA: United States, Beatty Press,.

Duran, N. Tezer, E. (2005). Sanat Benlik-Kavramı Ölçeği’nin geçerliği ve güvenirliği üzerine bir çalışma. Türk Psikolojik Danışma ve Rehberlik Dergisi, 3(23),47-55.

Emre, R. (2008). Türkiye Futbol Antrenörleri Derneği Konya Şubesine üye antrenörlerin sosyo-ekonomik ve kültürel yapılarının tespiti ve değerlendirilmesi. Doktora Tezi, Selçuk Üniversitesi Sağlık Bilimleri Enstitüsü, Konya.

Fidan, S. (2002). Türkiyedeki Ve Dünya’daki Elit Cimnastikçilerin Sosyo-Ekonomik Analizi. Yüksek Lisans Tezi, Marmara Üniversitesi Sağlık Bilimleri Enstitüsü, İstanbul.

Gönülaçar, Ö. (2010). T.V.F. antrenör kurslarından mezun olan voleybol antrenörleri ile M.E.B. voleybol etkinlikleri içerisinde yer alan beden eğitimi öğretmenleri arasındaki bazı sosyo-ekonomik ve eğitim düzeylerinin karşılaştırılması. Yüksek Lisans Tezi, Gazi Üniversitesi Sağlık Bilimleri Enstitüsü, Ankara.

Karasar, N. (2010). Bilimsel Araştırma Yöntemi 21. Basım, Ankara:Nobel Yayın Dağıtım.

Kılınç, P. (2012). Gençlik Hizmetleri Ve Spor İl Müdürlüğünde Çalışma Koçların Memnuniyetinin Belirlenmesi. Yüksek Lisans Tezi, Karamanoğlu Mehmetbey Üniversitesi Sosyal Bilimleri Enstitüsü, Karaman.

Konter, E. (2007). Antrenörlerin Ve Sporcuların Cinsiyetlerine Göre Liderlik Gücü Algıları. Spormetre Beden Eğitimi Ve Spor Bilimleri Dergisi, 5(2), 85-90.

Milroy, J. Orsini, M. Abundo, M. Sidman, C. (2013). College students' perceived wellness among online, face-toface, and hybrid formats of a lifetime physical activity and wellness course. American Journal of Health Education, 44,252-258.

Odabaş, İ. (2017). The Turkish Language Adaptation of TheWellness Self-Perceptions Scale: A Validity and Reliability Study. International Journal of Business and SocialScience, 8(6),42-49.

Oka, A. (1986). Sosyalleşme Süreci ve Spor. Yüksek Lisans Tezi, Gazi Üniversitesi Sosyal Bilimler Enstitüsü, Ankara. 
Toklu, O. (2010). Tenis antrenörlerinde liderlik özellikeri ve öz yeterlilik arasındaki ilişkinin belirlenmesi. Doktora Tezi, Selçuk Üniversitesi Sağllk Bilimleri Enstitüsü, Konya

Yıldız, A. (2019). Bursada yaşayan voleybol antrenörlerinin durumluk ve sürekli kaygı düzeylerinin yaş, belge türü çalıştırdığı takım düzeyi ve sporcu özgeçmişine göre incelenmesi. Yüksek lisans Tezi. Uludağ Üniversitesi Eğitim Bilimleri Enstitüsü, Bursa.

Yolaç, A. (2020). Farklı voleybol liglerindeki takımlarda görev alan voleybol antrenörlerinin sosyo-ekonomik faktörler ve iyilik hali yönünden karşılaştırılması. Yüksek Lisans Tezi. Marmara Üniversitesi Sağlık Bilimleri Enstitüsü, İstanbul. 